\title{
Angiographic Studies of Quinton-Scribner Arteriovenous Cannulae
}

\author{
J. R. DATHAN,* M.B., B.S., M.R.C.P. ; J. M. A. THOMPSON,* M.B., B.CHIR., M.R.C.P. \\ B. S. WORTHINGTON, $\dagger$ M.B., B.SC., D.M.R.D.
}

[With Special Plate facing Page 22]

British Medical fournal, 1969, 4, 20-22

\begin{abstract}
Summary : An analysis of 86 angiographic studies of Quinton-Scribner shunts has shown that these may be very useful in determining the cause and helping in the management of poorly functioning cannulae in patients on regular haemodialysis treatment.
\end{abstract}

\section{Introduction}

Gaining access to the circulation is the most outstanding problem in regular haemodialysis treatment today. The most widely used means are modifications of the Quinton-Scribner Silastic Teflon cannula (Quinton et al., 1961, 1962 ; Sevitt et al., 1964 ; Ramirez et al., 1966 ; Hawkins and Robinson, 1967 ; McDonald and Waterhouse, 1967 ; Hoeltzenbein, 1968, 1969 ; Scribner et al., 1969). Although the introduction of this cannula was largely responsible for the recent rapid development of regular dialysis treatment, it is now the major limiting factor in the efficiency of this form of therapy. The natural history of the Silastic Teflon arteriovenous cannula is still not defined (Clarke and Parsons, 1966 ; Rentan and Lewis, 1966 ; Clunie et al., 1967 ; Glashan and Walker, 1968 ; Gombos et al., 1968 ; Papadimitriou et al., 1969). Many suggestions have been made for the prolongation of cannula life, from mandatory anticoagulation (Wing et al., 1967b) to wrapping the limb in lanolin (Kopp et al., 1968). There is, however, no general agreement. Sporadic reports on the use of angiography to assess cannula problems have appeared (McDonald and Waterhouse, 1967 ; Fritzer et al., 1968 ; Sinclair, 1968). This paper presents the results of angiographic studies performed by the London Hospital Dialysis Unit in the past 12 months. It provides some information on the natural history of the arteriovenous cannula and shows how radiology can determine the cause and guide the management of poorly functioning cannulae.

\section{Method}

Cannula problems may arise gradually or suddenly. Gradual deterioration is detected in routine dialysis by bubble flowmetering. The distinction between arterial and venous limb failure is well known, and is important. If the venous limb fails the flow is poor and the pressure measured nearest to it, usually at the bubble trap, will be high. If the arterial limb fails the flow will be poor but the bubble trap pressure will be normal. If flow ceases altogether a standard declotting procedure is used (Hegstrom et al., 1961 ; Pendras and Smith, 1966 ; Anderson et al., 1968). If any flow at all is achieved the patient is heparinized, the area of the cannula is warmed with an electrical heat pad, and the patient is re-examined after about half an hour. An electromagnetic flowmeter is sometimes used to check the flow through the shunt, after attempted declotting procedures. If the flow remains inadequate and the artery is judged to be normal, only the venous cannula is examined angiographically; otherwise both cannulae are exam-

* Lecturer in Medicine.

† Senior Registrar, Department of Radiology.

The London Hospital, London E.1. ined. Routine arteriography is avoided because of the pain it causes and its known serious complications (Drukker et al., 1969). Under aseptic conditions 2 to $3 \mathrm{ml}$. of Conray 280, warmed to $37^{\circ} \mathrm{C}$., is injected gently by hand into one limb of the cannula. The patient is warned before the arterial injection to expect a transient burning sensation in the limb. Films are taken by means of an overcouch tube with a cassette placed under the limb. The exposure is made to coincide with the end of the injection. If there is any question of poor alignment of the cannula within the vessel a second film is taken at right angles.

\section{Results and Discussion}

With this technique we have performed 86 angiographic examinations. The main findings are classified and discussed below. In this series the mean arterial cannula survival was 8.4 months, and that of the venous cannula 9.3 months. This is comparable to other published figures (Comty et al., 1967 ; Gombos et al., 1968; Wing et al., 1967a, 1967b ; Drukker et al., 1969).

The angiograms may be classified in the following ways: (1) thrombus in vessel, (2) spasm of vessel wall, (3) malalignment of cannula and vessel, (4) " aneurysms," (5) arterialization of veins (endarterial proliferation), (6) technical artifacts, and (7) unexplained abnormalities. These appearances are discussed below. For subsequent comparison a normal arteriogram and a normal venogram are shown in Figs. 1 and 2 (Special Plate) respectively.

\section{Thrombus in Vessels}

Thrombus is seen as an irregular intraluminal filling defect of variable appearance. Thrombus may be seen adjacent to the cannula tip only (Special Plate, Fig. 5) or as a more extensive filling defect extending along the vessel (Special Plate, Fig. 3). Where thrombus is distinctly seen a fibrinolytic agent injected into the vessel may restore satisfactory function (Hegstrom et al., 1961 ; Vermylen et al., 1967 ; Anderson et al., 1968 ; Kjellstrand et al., 1968 ; Aviram et al., 1969). We have successfully used the method first described by Anderson et al. in which 50,000 international units of streptokinase in $5 \mathrm{ml}$. of normal saline is injected as a single dose into the affected cannula, which is then clipped off for two hours (Special Plate, Figs. 3 and 4). Urokinase and protease (Bennhold et al., 1969) have also been used.

Thrombus in arteries is less common. The appearance and management are the same as with veins, and streptokinase has also been used successfully.

If recannulation is necessary it is most important to cut down on to a healthy vessel through a new incision and to cannulate in the normal way. The vessel may then be followed distally and the old cannula removed. A mistake commonly made is to attempt recannulation through an old incision and to be unable to find the vessels among the fibrous tissue except by extending the incision. Angiography has proved of great help in enabling us to choose the site of incision on to a healthy vessel above the obstruction. 


\section{Spasm of Vessel Wall}

Spasm in veins is seen as a smooth symmetrical narrowing of the lumen, either localized as in Fig. 3 or more extensively as in Fig. 6. It can be caused by inflammation, by overdistension-for example, when solutions are injected intravenously under pressure as in declotting-or by injection of cold solutions. Local heating relaxes spasm. Local anaesthetics and papaverine are also used (Clarke and Parsons, 1966). Spasm commonly accompanies thrombosis. A common mistake is to inject more and more saline into a vein in the hope of improving the flow. If any flow at all is achieved it is best to heparinize the patient, apply local heat, and wait. Arteries seem to behave as if they are subject to spasm. In this series, however, it was not possible to demonstrate radiographically any arterial spasm resembling that seen in veins. Sometimes an artery appears to be uniformly narrow, but this may not be significant. The arterial lumen of ten has a beaded appearance and should not be mistaken for arterial spasm (see artifact below).

\section{Malalignment of Cannula and Vessel}

Poor alignment of the cannula tip with the vessel of ten causes trouble through thrombosis (Special Plate, Figs. 5 and 6). In this series poor alignment was the most important cause of loss of arteries in the arm. Occasionally buckling of the arterial wall may cause malalignment and give rise to intermittent flow by the mechanism described below and shown in Fig. 7 (Special Plate). In such cases it appears that during cannulation the cannula tip has been advanced too far, thus buckling the artery and causing the open end of the Teflon to rest against the arterial wall. Once the Teflon tip is securely tied to the vessel this may be avoided by exerting mild tension in the line of the artery by means of an anchoring suture.

\section{"Aneurysms"}

Aneurysm formation is a known complication (Kulatilake, 1968). It is usually described as "mycotic." The reason for this is not clear. The aneurysm occurs as a result of mechanical trauma to the arterial wall by the Teflon cannula tip or by the sutures tying it into the vessels (Glashan and Walker, 1968). Blood leaks from the artery into the surrounding tissue and forms a pseudoaneurysm. Two cases have occurred in arteries; in both of these the cannula had been in situ for many months without any evidence of infection (Special Plate, Fig. 8). We have also seen one case of pseudoaneurysm formation in a vein. At operation in that case there appeared to be an aneurysm attached to the vein. Microscopically the aneurysm was lobulated thrombus. Bleeding had occurred into the vein wall and later into the surrounding fat. The elastic of the wall was absent at one point. Non-specific chronic inflammatory tissue and foreign body reaction to suture material was also present. The significance of this is doubtful, but it could mean that the suture material tied round the vein and holding it on to the Teflon tip had been too tight, thus causing ischaemic damage to the vein wall. This possibility is also demonstrated in Fig. 16 (Special Plate), the suture being so tight that it is actually kinking the Teflon; this could well cause ischaemic necrosis (Glashan and Walker, 1968).

\section{Arterialization of Veins}

The arteriovenous connexion provided by the cannula could behave in the same way as a Cimino-Brescia fistula (Brescia et al., 1966), in the sense that the veins would become prominent and dilated, and sometimes the main vein does, but usually only in the early stages. Gradually some change takes place in the vein wall and the lumen becomes narrowed (Special Plate, Fig. 10). We have noticed that sometimes the narrow segment extends only as far as the nearest valve (Special Plate, Fig. 11). This change does not occur with direct arteriovenous fistulae: it must in some way be connected with the presence of the Teflon part of the cannula. Perhaps the rigid tip of the cannula traumatizes the vein and initiates a reaction in the wall. It is hard to see how turbulence created by a cannula could alone cause changes so consistently different from turbulence in a direct arteriovenous fistula. It is possible that this appearance could be caused by the incorporation of thrombus into the vein wall (Glashan and Walker, 1968). We were unable to demonstrate a single example arising in a cannula where clotting had never occurred. It is suggested that cases such as these are most likely to benefit from anticoagulant therapy.

\section{Technical Artifacts}

A number of technical artifacts are shown in order that their appearance would be recognized and that they would not be confused with pathological phenomena.

Air.-Occasionally small air bubbles may be injected (Special Plate, Fig. 12). Their rounded appearance easily distinguishes them from thrombus.

Beaded Appearance of Arteries.-All retrograde arteriograms have a beaded appearance to some extent, and Fig. 13 (Special Plate) is a good example. This "beading" results from the opposing movement of blood and contrast medium (Mayall, 1964 ; Sinclair, 1968). It should not be mistaken for spasm, and is consistent with normal function.

Streaming.-A linear opacity commonly seen in venography (Special Plate, Fig. 14) should not be confused with linear thrombus (Figs. 3 and 6). It is caused by blood which has not been flushed out by contrast medium, and is distinguishable by the smooth parallel lines.

Possible Flow Artifact.-Fig. 15 (Special Plate) is an arteriogram which shows an apparent filling defect near the tip of the Teflon cannula. This finding is not uncommon. A second arteriogram performed the following day failed to demonstrate the abnormality, which, however, returned a day later. Sinclair (1968) suggested that apparent filling defects may be caused by turbulence. The history here could support that idea, but other interpretations are possible.

\section{Unexplained Abnormality}

A large number of angiograms show an opacity apparently projecting into the lumen from the vessel wall, immediately adjacent to the Teflon tip (Special Plate, Fig. 16). The appearance is identical in arteries and veins and is compatible with normal function.

We would like to acknowledge the assistance of Professor J. M. Ledingham, Professor C. Wilson, the staff of Hanbury Dialysis Unit, Dr. R. S. Murray and the staff of the department of radiology, and Mr. R. Ruddick and the staff of the photographic department, the London Hospital, in the preparation of this paper.

Addendum.-Since submitting this paper De Palma et al. (1969) have published the findings of 56 angiographic examinations. To avoid the pain of arterial injection they infuse 2-4 $\mathrm{ml}$. of $1 \%$ procaine into the arterial cannula, followed by Conray 400 diluted as follows: 4 parts Conray 400, 3 parts normal saline, 1 part $1 \%$ procaine.

REFERENCES

Anderson, D. C., Martin, A. M., Clunie, G. J. A., Stewart, W. K., and Robson, J. S. (1968). In Dialysis and Renal Transplantation.' Proceedings of the 4th Conference of the European Dialysis and Trans plant Association, edited by D. N. S. Kerr, p. 55. Amsterdam, Excerpta Medica. 
Aviram, A., Kenyan, A., and Czaczkes, J. W. (1969). In Dialysis and Renal Transplantation: Proceedings of the 5th Conference of the European Dialysis and Transplant Association, edited by D. N. S Kerr, p. 46. Amsterdam, Excerpta Medicá.

Bennhold, I., Froese, P., Scholz, A.,. and Kessel, M. (1969). In Dialysis and Renal Transplantation: Proceedings of the 5 th Conference of the European Dialysis and Transplant Association, edited by D. N. S. Kerr, p. 50 . Amsterdam, Excerpta Medica.

Brescia, M. J., Cimino, J. E., Appel, K., and Hurwich, B. J. (1966). New England Fournal of Medicine, 275, 1089.

Clarke, P. B., and Parsons, F. M. (1966). British Medical fournal, 1, 1200 .

Clunie, G. J. A., Martin, A. M., and Nolan, B. (1967). British Medical fournal, 3, 88 .

Comty, C. M., Baillod, R. A., Crockett, R., and Shaldon, S. (1967). In Replacement of Renal Function: Proceedings of the 3rd Confer ence of the European Dialysis and Transplant Association, edited by D. N. S. Kerr, p. 98 . Amsterdam, Excerpta Medica.

De Palma, J. R., Golding, A., and Maxwell, M. H. (1969). Transactions. American Society for Artificial Internal Organs, 15, 278

Drukker, W., Schouten, W. A. G., and Alberts, C. H. R. (1969). In Dialysis and Renal Transplantation: Proceedings of the 5th Conference of the European Dialysis and Transplant Association, edited ence of the European Dialysis and Transplant Associ.
by D. N. S. Kerr, p. 3. Amsterdam, Excerpta Medica.

Fritzer, W., Jahn, O., and Pinggera, W. (1968). In Dialysis and Renal Transplantation: Proceedings of the 4 th Conference of the European Dialysis and Transplant Association, edited by D. N. S. Kerr, p. 366. Amsterdam, Excerpta Medica.

Glashan, R. W., and Walker, F. (1968). British fournal of Surgery, 55, 189.

Gombos, E. A., Hendler, E. D., and Hendler, R. G. (1968). In Dialysis and Renal Transplantation: Proceedings of the 4th Conference of the European Dialysis and Transplant Association, edited by the European Dialysis and Transplant Association,

Hawkins, J. B., and Robinson, B. H. B. (1967). British Medical fournal, $4,226$.

Hegstrom, R. M., Quinton, W. E., Dillard, D. H., Cole, J. J., and Scribner, B. H. (1961). Transactions. American Society for Artificial Internal Organs, 7, 47.

Hoeltzenbein, J. (1968). In Dialysis and Renal Transplantation: Procedings of the 4th Conference of the European Dialysis and Trans plant Association, edited by D. N. S. Kerr, p. 39. Amsterdam, Excerpta Medica.

Hoeltzenbein, J. (1969). In Dialysis and Renal Transplantation: Proceedings of the 5th Conference of the European Dialysis and Transplant Association, edited by D. N. S. Kerr, p. 370. Amsterdam, Excerpta Medica.
Kjellstrand, C. M., Lindergård, B., and Boijsen, E. (1968). In Dialysis and Renal Transplantation: Proceedings of the $4 \mathrm{th}$ Conference of the European Dialysis and Transplant Association, edited by D. N. S. Kerr, p. 61. Amsterdam, Excerpta Medica.

Kopp, K. F., Crossman, D. F., and Frey, J. (1968). In Dialysis and Renal Transplantation: Proceedings of the 4th Conference of the European Dialysis and Transplant Association, edited by D. N. S. Kerr, p. 373. Amsterdam, Excerpta Medica.

Kulatilake, A. E. (1968). In Dialysis and Renal Transplantation: Proceedings of the 4th Conference of the European Dialysis and Transplant Association, edited by D. N. S. Kerr, p. 369 . Amsterdam, plant Association,

McDonald, H., jun, and Waterhouse, K. (1967). In Replacement of Renal Function: Proceedings of the 3rd Conference of the European Dialysis and Transplant Association, edited by D. N. S. Kerr, p. 337. Amsterdam, Excerpta Medica.

Mayall, G. F. (1964). Clinical Radiology, 15, 355.

Papadimitriou, M., Carrol, R. N. P., and Kulatilake, A. E. (1969). British Medical łournal, 2, 15.

Pendras, J. P., and Smith, M. P. (1966). Transactions. American Society for Artificial Internal Organs, 12, 222.

Quinton, W. E., Dillard, D. H., Cole, J. J., and Scribner, B. H. (1961). Transactions. American Societs for Artificial Internal Organs, 7, 60.

Quinton, W. E., Dillard, D. H., Cole, J. J., and Scribner, B. H. (1962) Transactions, American Society for Artificial Internal Organs, 8 ,

Ramirez, O., Swartz, C., Onesti, G., Mailloux, L., and Brest, A. N. (1966). Transactions. American Society for Artificial Internal Organs, 12, 220

Rentan, J. W., and Lewis, H. Y. (1966). Annals of Internal Medicine, 64, 284.

Scribner, B. H., Caner, J. E. Z., Buri, R., and Quinton, W. E. (1969). In Proceedings of the 6th Conference of the European Dialysis and Transplant Association. In press.

Sevitt, L., Comty, C., Rottka, H., and Shaldon, S. (1964). In Proceedings of the 1st Conference of the European Dialysis and Transplant Association, edited by D. N. S. Kerr, p. 271. Amsterdam, Scheltema and Hdima.

Sinclair, D. J. (1968). Clinical Radiology, 19, 287.

Vermylen, J., Amery, A., Dirix, R., and Verstraete, M. (1967). Lancet, 2, 1369 .

Wing, A. J., Curtis, J. R., and de Wardener, H. E. (1967a). British Medical fournal, 3, 143.

Wing, A. J., Curtis, J. R., de Wardener, H. E., and Evans, D. B. (1967b) In Replacement of Renal Function: Proceedings of the 3rd Conference of the European Dialysis and Transplant Association, edited by D. N. S. Kerr, p. 102. Amsterdam, Excerpta Medica.

\title{
Impact of Community-orientated Psychiatry on Marriage and Fertility of Psychotic Women
}

\author{
BARBARA STEVENS,* B.A., PH.D.
}

Summary : A large representative sample of psychotic $S$ women of reproductive age was selected from patients admitted to a London mental hospital during 1955-63 and followed up during the years of developing community care. Before first admission the probability of marriage of schizophrenics was three-quarters of that of corresponding normal women, and after admission it was just over one-third of normal. Fertility of schizophrenics was slightly reduced both before and after illness, and much of this reduction remains due to their being in hospital. The probability of marriage and fertility of women suffering from severe affective disorders was very similar to that found in the corresponding general population. Despite a lessening of differentials between patients and normal women since the impact of community care the probability of marriage of schizophrenics with abnormal personalities is still significantly reduced.

\footnotetext{
- Member of the Scientific Staff, M.R.C. Social Psychiatry Research
} Unit, Institute of Psychiatry, London S.E.5.

\section{Introduction}

During the first half of this century long-term institutional care characterized the lives of the mentally ill, and their probability of marriage and fertility appeared to be reduced when compared with the corresponding general population. In Germany Kallmann (1938) selected over 1,000 schizophrenics from patients admitted to a Berlin hospital between 1893 and 1902 , and followed them up until 1933 ; the proportion who eventually married was well below that expected on the basis of Berlin's general population, except among those with paranoid schizophrenia whose illness was of late onset. The fertility of non-paranoid schizophrenics was also below that of the general population. Essen-Möller (1935) analysed a large series of patients admitted to the Munich Psychiatric Clinic between 1904 and 1927, and found that the probability of marriage of schizophrenics after admission was between one-third and oneninth of that of the general population. The fertility of schizophrenics was low before the spread of birth control, and even after the fall in the German birth rate it was especially low 
FIG. 1.-Normal arteriogram.

Fig. 2.-Normal venogram.

These cannulae had been functioning normally for one month and continued to do so for a further nine months.

Fig. 3.-Venogram. Cannula in situ for four weeks. Local infection was followed by clotting in the venous cannula. Thrombus is seen as a long, irregular filling defect. Above this is a segment of vein narrowed by spasm.

FIG. 4.-Venogram. Same cannula as in Fig. 3 after streptokinase therapy, showing a diminution of thrombus and resolution of spasm. The vein functioned for a further 10 weeks.
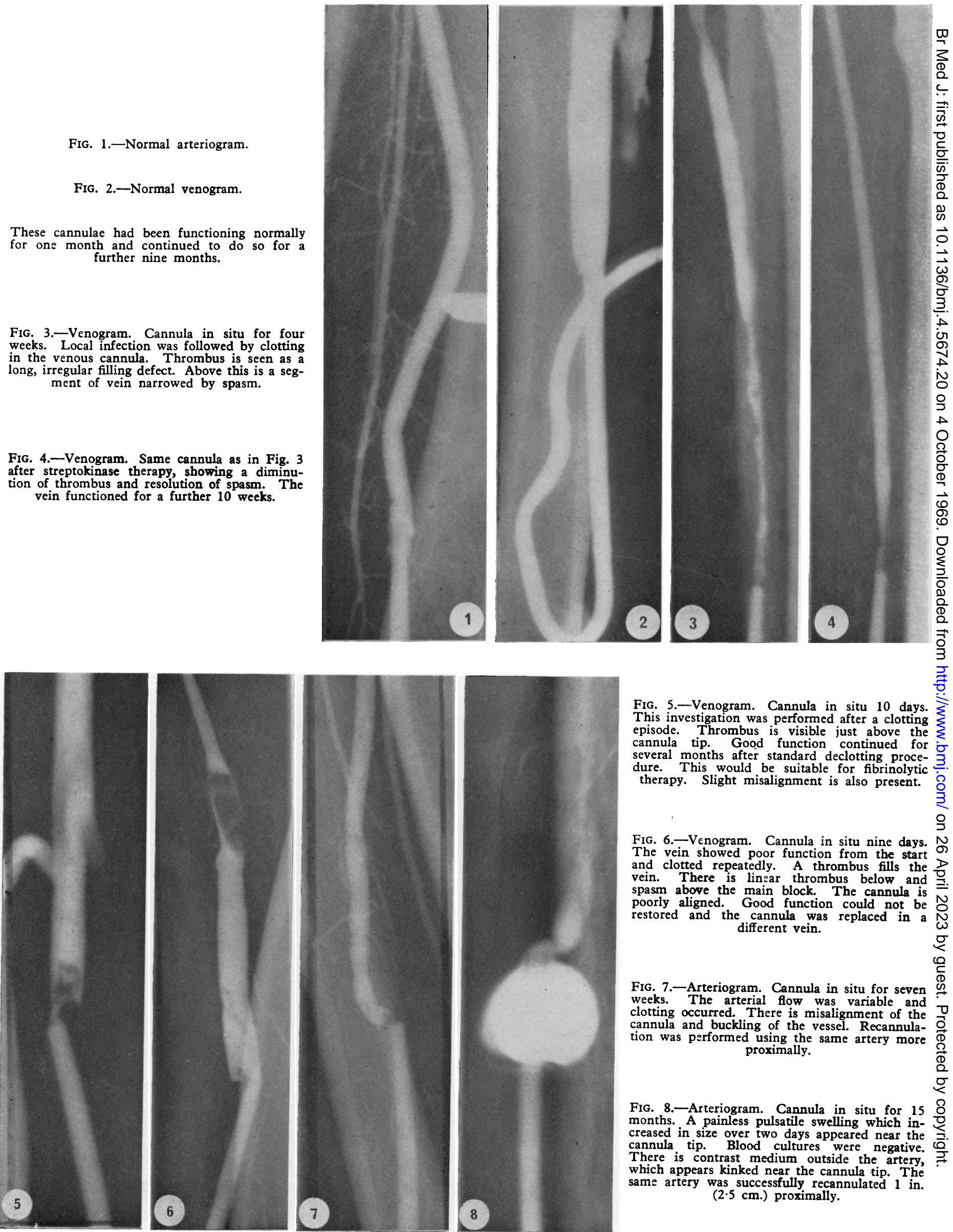

FIG. 5.-Venogram. Cannula in situ 10 days. This investigation was performed after a clotting episode. Thrombus is visible just above the cannula tip. Good function continued for several months after standard declotting proce- 3 dure. This would be suitable for fibrinolytic 3 . therapy. Slight misalignment is also present.

Fig. 6.-Venogram. Cannula in situ nine days. N The vein showed poor function and clotted repeatedly. A thrombus fills the $D$ vein. There is linear thrombus below and spasm above the main block. The cannula is poorly aligned. Good function could not be $N$ restored and the cannula was replaced in a $N$ different vein.

FIG. 7.-Arteriogram. Cannula in situ for seven weeks. The arterial flow was variable and clotting occurred. There is misalignment of the cannula and buckling of the vessel. Recannulation was performed using the same artery more proximally.

$$
\text { . }
$$

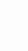




\section{J. R. DATHAN ET $A L$ : ANGIOGRAPHIC STUDIES OF QUINTON-SCRIBNER ARTERIOVENOUS CANNULAE}
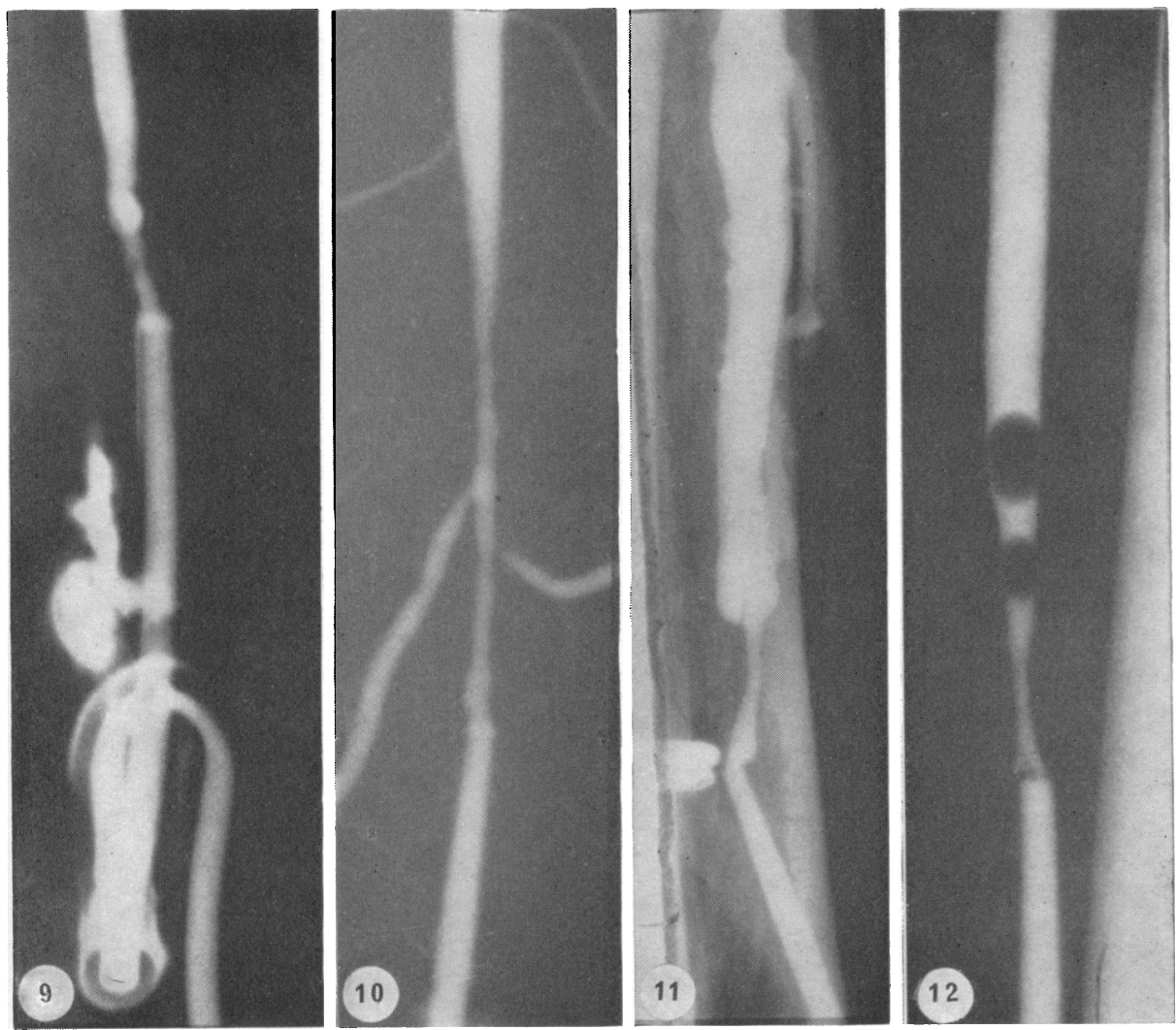

Fig. 9.-Venogram. Cannula in situ for three months. Persistent bleeding occurred from the venous cannula site. Venography shows contrast outside the vessel tracking along the Silastic tubing. The vein was recannulated more proximally.

Fig. 10.-Venogram. Cannula in situ three months. Poor venous flows initially interpreted as spasm became persistent. The venogram shows a long "narrow segment." One week later clotting occurred and the cannula was replaced.

FIG. 13-Arteriogram. Cannula in situ for two days, when repeated clotting occurred. Artery and vein had to be replaced two days later. This is a good example of beading.

Fig. 14.-Venogram. Cannula in situ for six months. The artery then failed. The vein was functioning normally at the time and has done so subsequently. A linear opacity is visible in the lumen.

FIG. 15.-Arteriogram. Cannula in situ for one month. The cannula clotted repeatedly. The vein was at fault initially, but later the artery failed to function. This arteriogram taken when the artery was functioning normally shows an apparent filling defect near the Teflon tip, which disappeared the next day, only to return later.

FIG. 16.-Venogram. Cannula in situ for two months. Repeated clotting occurred caused by malalignment of the artery. Vein clinically normal. There is a ring-shaped filling defect adjacent to the Teflon tip. Flow was normal and the cannula continued to function normally for a further two months.
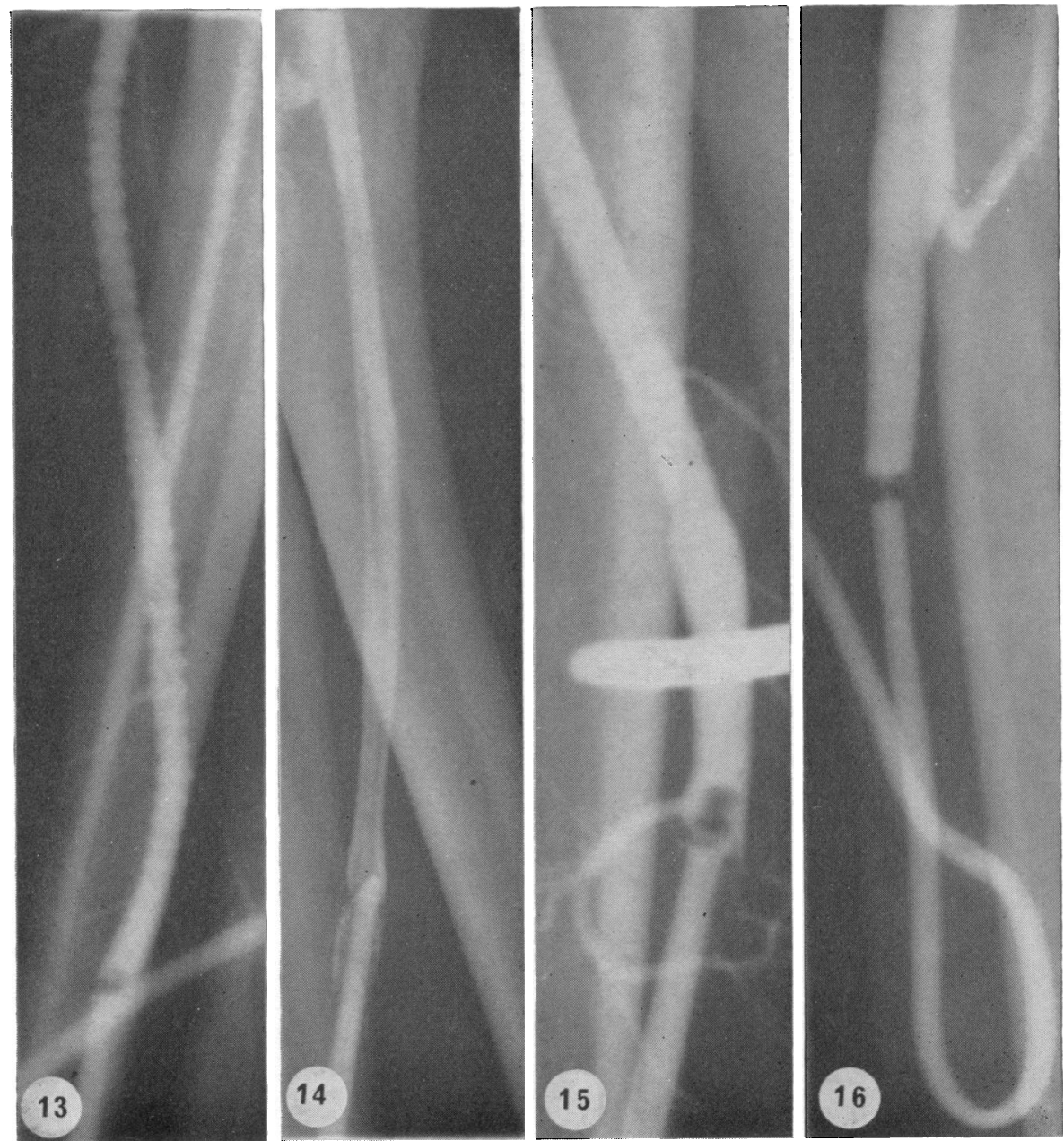

Fig. 11.-Venogram. Cannula in situ for four months. The cannula is sited in the venae comitantes of the posterior tibial artery. Poor flows were noted, followed by repeated clotting. There is poor alignment of the cannula, which anticoagulants good flows returned, and a sccond venogram, performed some months later, was identical. The cannula continued to function 14 months after insertion (10 months after this picture). In other cases venae comitantes in the leg have been used successfully. The cannula can be anchored and made completely immobile.

Fig. 12.-Venogram. Cannula in situ three months ; investigation performed after a clotting episode. The cannula functioned for a further six months. Spasm is present and the lumen contains two air bubbles. 